\title{
Arte e vida, vida e(em) arte: entrelaçamentos a partir de Vygotsky e Bakhtin
}

\author{
Art and life, life and(in) art: interconnections from Vygotsky and Bakhtin
}

Alice Casanova dos Reis ${ }^{[a]}$, Andréa Vieira Zanella ${ }^{[b]}$

\footnotetext{
[a] Doutora em Psicologia Social pela Universidade de São Paulo (USP), professora do curso de Psicologia do CESUSC, Florianópolis-SC, Brasil, e-mail:

alicecasanova@yahoo.com.br

${ }^{[b]}$ Doutora em Psicologia da Educação pela Pontifícia Universidade Católica de São Paulo (PUC-SP), professora associada da Universidade Federal de Santa Catarina (UFSC), Florianópolis-SC, Brasil, e-mail: andreavz@uol.com.br
}

Recebido: $12 / 07 / 2013$ Received: 07/12/2013

Aprovado: $12 / 09 / 2013$ Approved: 09/12/2013

\section{Resumo}

0 presente artigo tem como objetivo discutir o entrelaçamento entre a arte e a vida. A discussão parte da apreciação estética/leitura de uma exposição fotográfica, aqui (re)vista como um dispositivo que provoca o olhar às relações entre o vivido e sua (re)apresentação via discurso artístico. A partir daí, busca-se compreender a imbricação entre a arte e a vida, através do diálogo com o pensamento de Vygotsky e Bakhtin. Em ambos os autores há uma visão psicossocial da arte, compreendida como um modo específico de relação social que se diferencia pela ruptura aos instituídos, inaugurando novas possibilidades. Abordam-se as perspectivas e principais ideias dos dois autores, tendo como eixos de análise, em Vygotsky, a questão da arte como transformação da vida e, em Bakhtin, o problema da arte como enformação estética da existência. Conclui-se que a relação entre vida e arte é dialética e dialógica, afirmando-se a potência da arte no desenvolvimento do ser humano para a reinvenção da própria vida, concebida como obra inacabada.

Palavras-chave: Arte. Vida. Vygotsky. Bakhtin.

\section{Abstract}

This article aims to discuss the entanglement between art and life. The discussion starts from the aesthetic appreciation/reading of a photographic exhibition, (re)viewed here as a device that provokes the eye towards the relationship between the lived experience and its (re)presentation through the artistic discourse. From there, it was sought to understand the imbrication between art and life through the dialogue with the thinking of Vygotsky and Bakhtin. Both authors share a psychosocial view of art, understood as a specific form of social relationship that differs by the rupture with what is instituted, opening up new possibilities. The perspectives and main ideas of the two authors are addressed, being the axes of analysis, in Vygotsky, the question of art as life transformation and, in Bakhtin, the problem of art as aesthetic shaping of existence. It was concluded that the relationship between life and art is dialectical and dialogical, stating its power in the development of human beings for the reinvention of life itself, conceived as an unfinished work.

Keywords: Art. Life. Vygotsky. Bakhtin. 


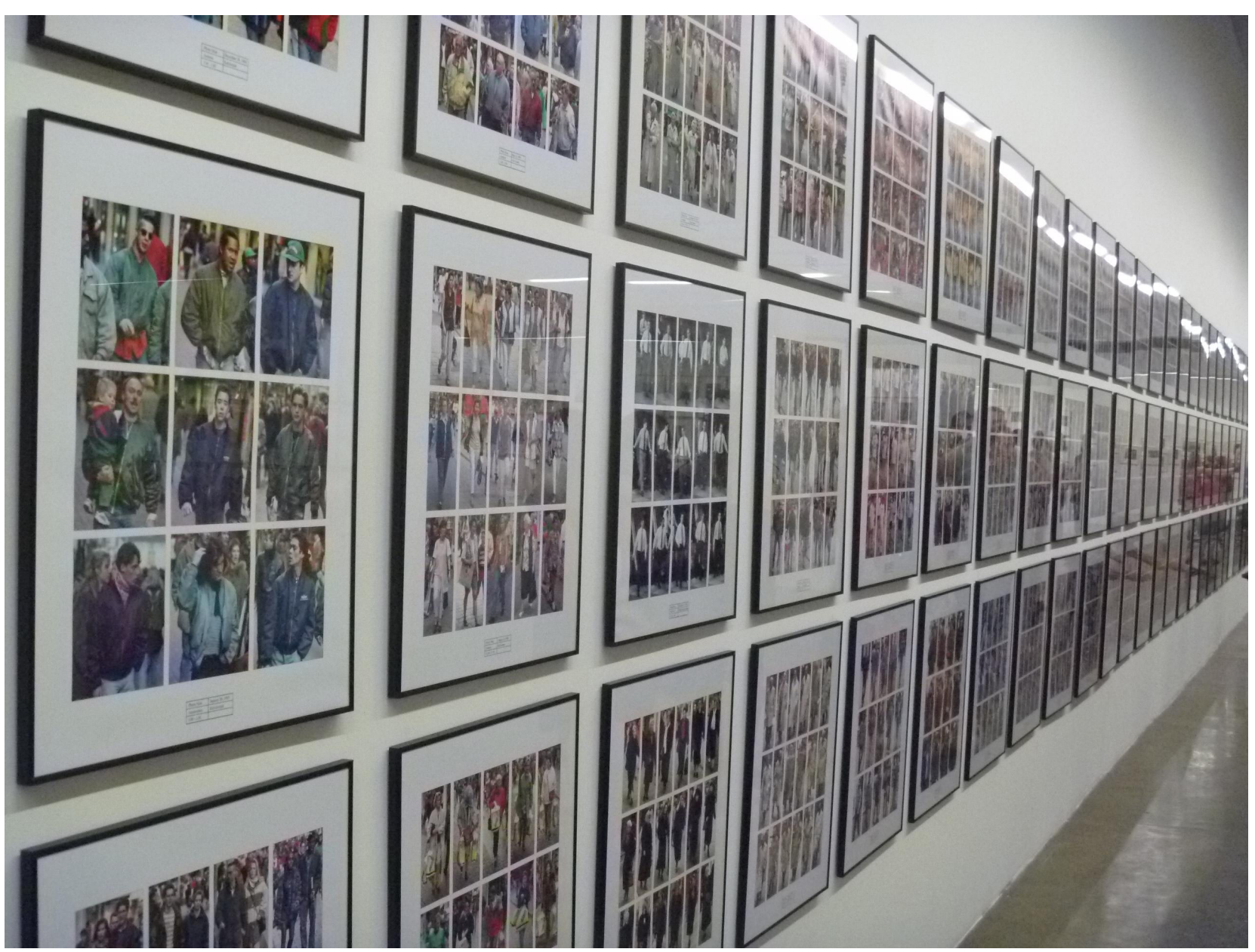

Figura 1- Foto do acervo de uma das autoras

Uma profusão de imagens, a compor um pressuposto mesmo! Pressuposto, por certo, a desafiar respostas ligeiras, a tensionar olhares apressados. A unicidade aparente, a preencher uma extensa parede branca com retângulos uniformes, provoca a leitura de seus entres, entrelinhas, entreimagens, entretantos... E dentre esses entres, os entrerretângulos também se apresentam como provocação ao olhar, ao evocarem possíveis cruzes, cruzamentos, jogos, labirintos, caminhos...

Sentidos vários, continuidades infindas, sugeridos pelo artífice da disposição dos retângulos na parede e também por quem produziu a imagem do conjunto de imagens, via escolha do ângulo e posição da câmara fotográfica que encaminham o olhar para certa direção, alimentada pelas linhas (ora definidas, ora esfumaçadas) e tons (in)definidos das margens superior e inferior que sugerem um sem fim.

Circunscritos por finas molduras em preto, esses evidentes retângulos acolhem outros tantos, mas não quaisquer. São imagens multiplicadas por 3 ou 4 , porém condensadas em um suposto mesmo - o retângulo formado pelo conjunto de imagens mais o passepartout branco e a fina moldura preta que o delimita - que rapidamente oblitera a percepção da diferença. Fina moldura preta, larga borda branca, $12,15,18$ imagens, à distância, de certo modo indiscerníveis, sugerindo mera repetição.

Essas imagens soam como agregados de volumes com intensidades variadas, entoados pelas cores que em vários destes retângulos se destacam. Predomínios de cores escuras, ou cores claras, ou vibrantes, ou nem tanto... E misturas, misturas, a tensionar o rápido caminho da categorização elementar. Caminhos outros são, então, cunhados com a aproximação em relação ao suposto mesmo e, nesse movimento, se revelam outras possibilidades de leitura, e outras, e outras.

Os volumes ganham contornos e revelam corpos encobertos por tecidos de diferentes texturas, 
cores, estampas - listrados, xadrezes, lisos; vermelhos, azuis, verdes, brancos, amarelos, pretos; casacos compridos, jaquetas curtas, ternos, saias, vestidos, sáris, burcas; bonés, chapéus, boinas; pessoas carregando sacolas de diferentes lojas, pessoas carregando sacolas de uma mesma loja; pessoas empurrando carrinhos com bebês, pessoas segurando bebês no colo envoltos em mantas com personagens de desenhos infantis; pessoas acompanhadas, sós, apressadas e outras nem tanto.

0 conjunto de imagens funciona como um atractor a fixar o olho de quem olha, a provocar sensibilidades com sua potente atração visiva (Canevacci, 2008). Rapidamente, quem olha os iniciais retângulos com vários retângulos outros, vai se enredando em uma trama que conecta as tantas pessoas ali retratadas, anônimos transeuntes em cidades várias. Pessoas quaisquer, capturadas em suas idas e vindas cotidianas, aproximadas umas das outras em virtude de características supostamente pouco expressivas e cujo olhar do fotógrafo alçou a um lugar de importância. E é isso o que faz a fotografia, como afirma Sontag (2004, p.41), pois "não há como suprimir a tendência, inerente a todas as fotos, de conferir valor a seus temas".

Da vida o fotógrafo/artista holandês Hans Eijkelboo recolheu o material para produzir a obra que expôs na Bienal de São Paulo de 2012, intitulada Foto anotações - Uma seleção do diário fotográfico 1992-2012. Fragmentos dessa obra, que ocupava uma extensa parede do terceiro andar do Pavilhão de Exposições da Bienal, no Parque Ibirapuera, na capital paulista, são apresentados nas fotografias aqui referidas. Anotações, diário, o intervalo de 20 anos, são informações que nos dão a dimensão do labor do artista e de seu acurado olhar, tanto em relação aos cotidianos capturados quanto ao defrontar-se com tantas imagens e pacientemente

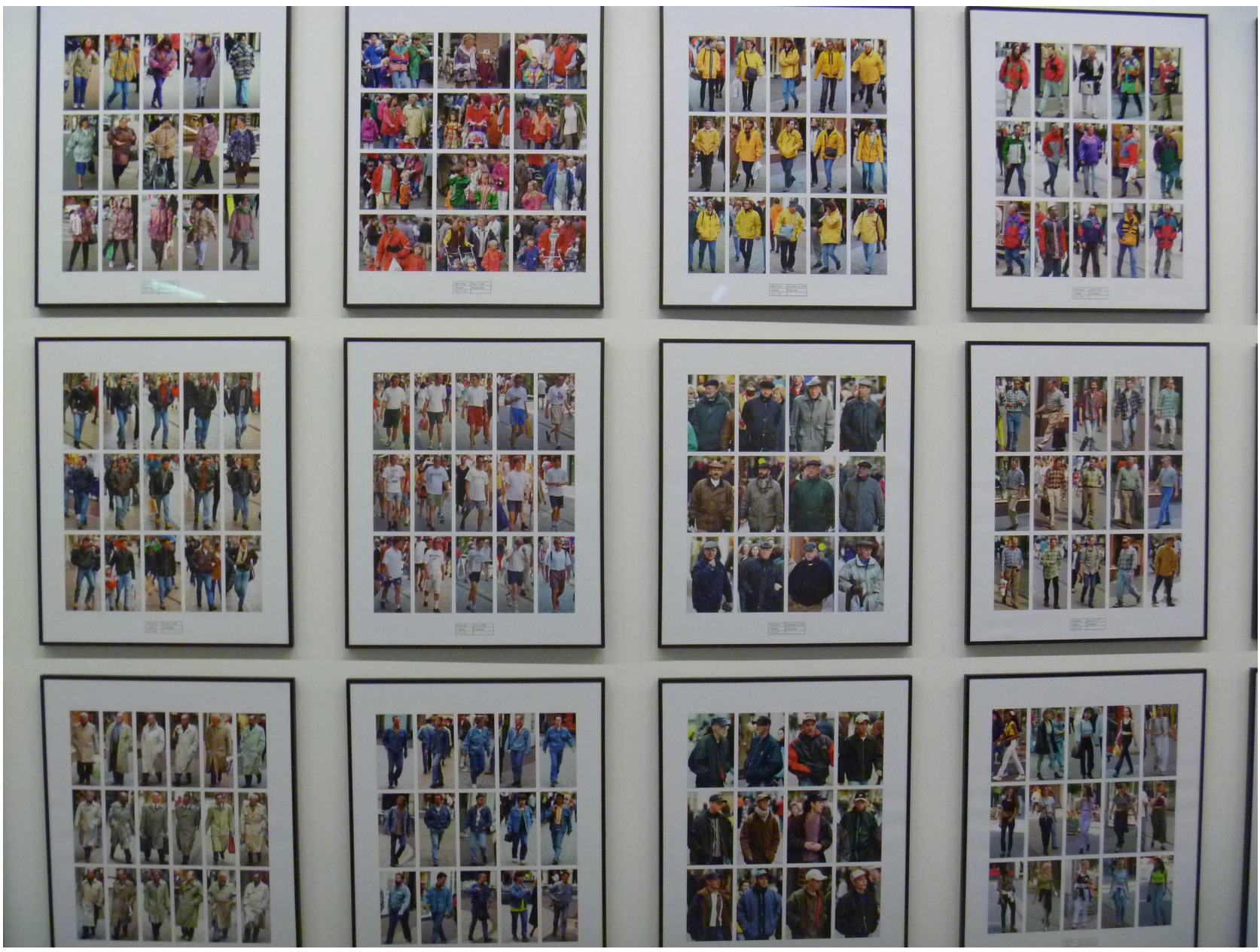

Figura 2 - Foto do acervo de uma das autoras 
selecionar algumas para dar o devido acabamento e transformar em obra de arte. Obra atractor produzida via imersão na vida e seu distanciamento, a provocar nos leitores a problematização da arte e da própria vida como seu fundamento. A provocar em nós, leitoras de sua obra e autoras deste artigo, a necessidade de discutir o entrelaçamento arte-vida, o que aqui faremos no diálogo com as contribuições de Lev Semionovitch Vygotsky e de autores do Círculo de Bakhtin ${ }^{1[c]}$.

Vygotsky (1896-1934), fundador da psicologia histórico-cultural, iniciou sua trajetória acadêmica dedicando-se a questões relacionadas ao campo da arte. Um de seus primeiros e mais importantes escritos foi o livro Psicologia da Arte (1998), onde enfoca a atividade de uma perspectiva psicossocial, dedicando-se especialmente ao desenvolvimento de um método para análise da obra de arte e ao problema da recepção estética. Outro, dentre os textos Vygotskyanos fundamentais à nossa reflexão, é $A$ imaginação e arte na infância (1990), onde o autor desenvolve sua teoria acerca da atividade criadora.

Bakhtin (1895-1975), filósofo russo e teórico do campo da linguagem, desenvolveu em seus estudos literários uma teoria estética que se sobrepôs às correntes dominantes da época, as quais reduziam a arte ora aos seus aspectos objetivos (formalistas), ora aos subjetivos (expressionistas). Em contrapartida, propunha uma análise sociológica da arte, concebida como modo específico de comunicação social, no qual a vida ganhava enformação estética. Nas obras Estética da criação verbal (2003), Discurso na vida e discurso na arte (1976), escrito em coautoria com Voloshinov, e Questões de estética e literatura (1993), encontram-se algumas das ideias mais representativas do pensamento do autor acerca da temática aqui abordada.

As discussões tanto de Vygostki como de Bakhtin se enraízam no materialismo histórico e dialético. Um dos pressupostos epistemológicos fundamentais nessa matriz é a concepção de ser humano como ser social, ao mesmo tempo produto e produtor do contexto histórico e cultural do qual ativamente

1 Círculo de Bakhtin faz referência a um grupo de intelectuais russos de diferentes áreas do conhecimento que se reuniu entre 1919 e 1929, entre os quais destacam-se Valentin Voloshinov, Pavel Medvedev e Mikhail Bakhtin. Sobre as ideias do Círculo de Bakhtin, ver Faraco (2009a). participa. A própria noção de social é articulada pelos autores de um novo ponto de vista: não mais como sinônimo de coletivo, algo separado/em oposição ao singular, mas o social enquanto relação. As interações com um outro presente/ausente são, portanto, constitutivas do próprio eu e seu fundamento (Barros, 2012a; Zanella, 2005).

Mas como compreender a arte, partindo dessa noção da indissociabilidade social/singular? Entendemos que a arte é uma forma específica de relação, cujas principais características iremos discutir neste texto tomando como ponto de partida um possível diálogo sobre as relações arte-vida nas perspectivas desses dois autores: em Vygotsky, a questão da arte como transformação da vida; em Bakhtin, a arte como enformação estética da existência.

\section{Arte como transformação da vida}

A arte imita a vida, afirma um velho ditado popular. Mas, para o escritor Oscar Wilde (1992), "a vida imita a arte muito mais do que a arte imita a vida" (p.51). Que existe uma profunda relação entre arte e vida é consenso geral, mas há que se perguntar se a base dessa relação de fato é a imitação de uma pela outra. Em nosso entender, a arte não é mimesis, não visa à reprodução da vida, mas à sua transformação: ela não duplica a vida, mas a multiplica de diversas formas e para direções variadas.

A noção de transformação é central na visão sobre a arte de Vygotsky $(1990,1998,2001)$, pois esta é por ele concebida como um processo que envolve tanto a transformação da realidade, quanto do próprio sujeito da ação. Seu pensamento o coloca à frente de seu tempo, inaugurando justo no campo da psicologia uma visão de arte que supera o psicologismo presente nas teorias estéticas da época. Em Psicologia da Arte (1998), Vygotsky propõe um método original de análise da obra de arte, sem reduzi-la ao autor ou ao espectador, mas tendo como objeto de estudo ela mesma. Dessa forma, era concebida numa perspectiva psicossocial, não como resultado de criação individual, mas como produto social e cultural. Ainda que enformada por uma pessoa, a unicidade na diferença possui, como afirma Vygotsky, um coeficiente social em toda atividade humana, seja esta protagonizada por uma, duas, quantas pessoas forem. Destaca o autor que "A arte 
é o social em nós, e se o seu efeito se processa em um indivíduo isolado, isso não significa, de maneira nenhuma, que as suas raízes e essência sejam individuais" (Vigotski, 1998, p.315).

Toda obra de arte apresenta, com intensidades e visibilidades variadas, materiais recolhidos pelo artista de sua própria vida e momento histórico em que vive, pautados pelas afecções produzidas em condições e contextos específicos e balizados pelas suas trajetórias. Tais materiais, agregados de um modo particular, se apresentarão para muitos outros como composição a ser admirada, tensionada, negada, devorada, deglutida ${ }^{2[d]}$. Composição com a qual é possível dialogar e a esta aderir, contrapor-se total ou parcialmente, enfim, discutir, para então recolher novos materiais a serem bricolados com outros de modo a compor um novo, que poderá ser fragmentado, aderido, recusado ${ }^{3[e]} \ldots .$.

Considerar a obra de arte em uma perspectiva psicossocial implica em afirmar a arte na arena da vida, pois é a partir das condições concretas de existência - históricas, sociais, culturais, políticas, econômicas - que se configuram (im)possibilidades para a criação, com destaque para a mediação das próprias tradições artísticas com que o artista se identifica ou às quais se contrapõe. Neste sentido, reiteramos que a criação pessoal se dá sempre em um contexto intersubjetivo e no intenso diálogo com a vida: "a obra de arte nunca reflete a realidade em toda a sua plenitude e verdade real, mas é produto sumamente complexo da elaboração dos elementos da realidade, de incorporação a essa realidade de uma série de elementos inteiramente estranhos a ela" (Vygotsky, 2001, p.329).

Esse movimento de reelaboração dos elementos da realidade e retorno a ela, a partir de um novo processo resultado da objetivação da atividade criadora e estranho a ela, nos permite afirmar que a arte,

2 A ideia de deglutição é emprestada do "Manifesto Antropofágico" de Oswald de Andrade e Tarsila do Amaral. Publicado em 1928, este manifesto afirmava a importância de se "devorar" as influências estrangeiras para a criação de uma arte brasileira. 0 processo de criação tal como concebido por Vygotsky, ao trabalhar com materiais recolhidos da vida e agregados de um modo particular, permite a analogia com o devorar e deglutir do manifesto antropofágico.

3 Esse é o modo como Vygotsky discute o processo de criação (ver Vygotsky, 1990). em suas diferentes modalidades, é um modo de objetivação estética de seu próprio artífice. Trata-se de objetivação da subjetividade que, no movimento de se apresentar a um outro e com este dialogar, é transformada novamente, sendo portanto a subjetividade social e historicamente constituída ${ }^{4[\mathrm{f}]}$.

Vygotsky (2000) nos permite (re)pensar a subjetividade fora das velhas dicotomias ao propor que o ser humano é o "conjunto de relações sociais, encarnado no indivíduo" (p.33). Essa encarnação se processa no corpo, na carne, e constitui as possibilidades de cada pessoa, sejam afetivas, cognitivas ou volitivas, a conotar as relações com o mundo, com os outros, consigo mesmo.

Mas de que modo a arte se relaciona à subjetividade? Para Vygotsky (1998), "a arte sistematiza um campo inteiramente específico do psiquismo do homem - precisamente o campo do seu sentimento" (p.12). As emoções e sentimentos humanos, aspectos constitutivos de nossos modos de ser, encontram expressão na arte por meio de um complexo processo de elaboração do qual resultam transformados, como se explicará a seguir. Vygotsky (1998) afirma que "toda emoção se serve da imaginação e se reflete numa série de representações e imagens fantásticas, que fazem as vezes de uma segunda expressão" (p.264). Emoções são transformadas no plano da imaginação, podendo ser objetivadas em imagens artísticas. $\mathrm{O}$ autor caracteriza as emoções estéticas como inteligentes pelo motivo de reterem sua manifestação externa, resolvendo-se em imagens da fantasia. A partir daí, desenvolve o conceito de catarse como central à compreensão da reação estética, definindo-o como um processo em que "as emoções angustiantes e desagradáveis são submetidas a certa descarga, à sua destruição e transformação em contrários" (Vygotsky, 1998, p.270). A catarse seria a complexa transformação dos sentimentos, cuja "resolução" se dá por meio da forma artística: "o artista sempre destrói o seu conteúdo pela forma" (p.271).

Lembramos que Vygotsky (1998) desenvolve sua teoria dialogando e se contrapondo às ideias dominantes na época, entre elas a reflexologia, a psicanálise e as estéticas subjetivistas. Desse modo, sua noção de catarse não se confunde com

\footnotetext{
4 Sobre subjetividade na perspectiva de Vygotsky e suas aproximações com Bakhtin, ver Barros (2012b).
} 
o conceito psicanalítico, pois não se trata simplesmente de uma descarga emocional, uma vez que "Por si só, nem o mais sincero sentimento é capaz de criar arte. Para tanto não lhe falta apenas técnica e maestria ....se faz necessário ainda o ato criador de superação desse sentimento, da sua solução, da vitória sobre ele" (Vygotsky, 1998, p.314). 0 autor também critica a teoria do contágio, elaborada por Tolstói, segundo a qual o sentimento individual seria expresso na arte, contagiando os demais. Essa teoria coloca o sujeito da recepção estética - o leitor, o ouvinte, o espectador - em uma posição passiva, sendo que para Vygostki (2001) também a percepção da arte demanda criação, pois "requer de quem percebe reunir em um todo e sintetizar os elementos dispersos da totalidade artística" (p.334), requer certa elaboração criadora do objeto apreciado. Não se trata apenas, portanto, de vivenciar empaticamente o sentimento do autor, mas encontrar sua própria catarse.

Fica claro que para Vygotsky (1998) a arte não é pura expressão dos sentimentos, mas "é uma espécie de sentimento social prolongado ou uma técnica de sentimentos" (p.308). Por meio da arte o homem pode comunicar aos outros diversos aspectos de sua história ou de sua concepção de vida, pois sua obra, ainda que não seja, necessariamente, biográfica, traz sempre impressa a marca de sua visão de mundo. Visão que pelo olhar estético (Reis, Zanella, França \& Da Ros, 2004), não exclusivo mas próprio à arte, vê, revê e transvê a vida pois, se a arte enlaça a vida, é para lhe produzir um novo desenlace.

A maior potência da arte está justamente em sua capacidade de transformação frente à realidade de que partiu, como tão bem explica Vygotsky (1998) na seguinte metáfora: "A arte está para a vida como o vinho para a uva" (p.307). Essa assertiva nos remete diretamente à natureza transformadora da arte, revelando sua alquimia frente à vida: "a arte recolhe da vida seu material mas produz acima desse material algo que ainda não está nas propriedades desse material" (p.308). Dado que na arte os sentimentos vitais são transformados e o material retirado da vida é recombinado pela imaginação de modo a se renovar, pode-se considerar o próprio processo de criação artística como um caminho possível à recriação da vida, à reinvenção de si a partir de novos modos de relação consigo, com o outro e com o mundo. Essa possibilidade é sintetizada por
Vygotsky (1998) ao trazer a ideia da "arte como método de construção da vida” (p.328).

Várias das discussões que aparecem no capítulo "Arte e Vida", em Psicologia da Arte, voltam a ser trabalhadas por Vygotsky (2001) em "A educação estética", capítulo que integra o livro Psicologia Pedagógica. Afirma-se o papel da educação estética na própria vida, não apenas no contato com obras de arte ou no aprendizado de técnicas artísticas, mas oportunizando espaços à vivência estética e à elaboração do que ela suscita em cada uma das pessoas. Como afirma o autor: "a vivência estética cria uma atitude muito sensível para os atos posteriores e, evidentemente, nunca passa sem deixar vestígios para o nosso comportamento" (Vygotsky, 2001, p.342).

Como a percepção ou criação de uma obra de arte me afeta? 0 que me provoca a pensar? Como isso se relaciona com minha vida? Essas são apenas algumas das questões que poderiam mediar um trabalho em educação estética, compreendendo-se "a estética enquanto dimensão sensível, enquanto modo específico de relação com a realidade, pautado por uma sensibilidade que permita reconhecer a polissemia da vida e transcender o caráter prático utilitário da cultura capitalística" (Zanella, 2006, p.36).

Para Vygotsky (2001), a educação estética deveria cumprir uma importante finalidade: oportunizar a vivência da transfiguração da realidade na arte e a consciência de que tudo aquilo que hoje nos parece dado foi também um dia criado, podendo ser, portanto, transformado. Como já afirmara anteriormente, "todos os objetos da vida diária, sem excluir os mais simples e habituais, vem a ser fantasia cristalizada" (Vygotsky, 1990, p.10). Com isso o autor nos fala justamente de uma relação estreita e intensa entre a arte e a vida, a vida transformada em arte, retornando à vida com uma nova força, rasgando o espaço do previamente estabelecido para forjar um lugar outro, onde um novo modo de ser se apresenta.

Trata-se, enfim, de levar a atividade criadora para o cotidiano, como possibilidade e direito de todos e não privilégio de alguns, concebendo-se criatividade não como um dom ou algo inato, mas tal como discutido por Zanella, Da Ros, Reis e França (2003), como um processo histórico e socialmente constituído.

Segundo Vygotsky (1990), a atividade criadora é complexa, envolve múltiplos processos psicológicos 
superiores que interagem entre si e com a realidade. A partir da descrição do autor, o circuito da atividade criadora compreende: 1) a percepção de aspectos da realidade e seu registro na memória; 2) a reelaboração desses elementos através da imaginação, com participação da cognição, emoções e vontade; 3) a objetivação do produto da fantasia, com a dimensão de um novo que o conota; 4) essa objetivação da atividade criadora se apresenta como material a ser percebido, dissociado, hibridizado com outros, em uma sucessão infinda dos momentos aqui referidos. 0 que se destaca nesse circuito é que, ao criar, o sujeito recria a realidade e, nesse movimento, recria a si mesmo, instituindo possibilidades outras para sua existência e para o contexto social.

Nas relações entre arte e vida afirmadas por Vygotsky, reconhecemos a possibilidade de toda e qualquer pessoa recriar a própria vida na/pela/ com a arte, um achado que abre à psicologia um vasto campo de pesquisa e atuação. Como (re)inventar nossas práticas neste campo que se configura pelo diálogo entre psicologia e arte? Embora algumas respostas já tenham sido produzidas nesse sentido (Da Ros, Maheirie \& Zanella, 2006; Zanella \& Maheirie, 2010), reportamo-nos aqui à indicação deixada pelo próprio Vygotsky (2001): “O que deve servir de regra não é o adornamento da vida, mas a elaboração criadora da realidade, dos objetos e seus próprios movimentos, que aclara e promove as vivências cotidianas ao nível de vivências criadoras" (p.352).

\section{Arte como enformação estética da existência}

Bakhtin e Voloshinov (1976) pensam a arte em uma perspectiva filosófica e sociológica, desenvolvendo uma teoria estética geral que transcende a própria literatura, por Bakhtin privilegiada dentre as demais linguagens artísticas, lançando as bases para auxiliar na compreensão também de outras artes. Talvez uma de suas maiores contribuições seja a concepção da arte em sua inter-relação concreta com a vida, superando tanto a visão essencialista quanto a determinista da mesma, em que é considerada mero reflexo da superestrutura ideológica.

Para Bakhtin e Voloshinov (1976), o problema está em reduzir a análise da arte ora ao material (caso do método formalista), ora à psique individual do autor ou espectador da obra em questão.
Se a redução das análises às psiques de autor ou espectador descontextualiza a obra de arte e desconsidera as condições de sua produção, a análise que se reduz ao material leva à fetichização da obra artística como artefato, supondo-lhe um dado sentido e excluindo criador e contempladores do campo de investigação. A superação de tais dissociações, que isolam uma parte tomando-lhe como se fosse o todo, pressupõe restituir a unidade constitutiva da arte, ou seja, sua ligação inexorável com a vida, pois "A arte, também, é imanentemente social; o meio social extra-artístico, afetando de fora a arte, encontra resposta direta e intrínseca dentro dela" (Voloshinov \& Bakhtin, 1976, p.2-3). Daí advém a compreensão que os autores trazem do estético enquanto uma formação social ou uma variedade do social, dimensão indissociável da arte.

A ideia da arte como uma espécie de resposta ao meio social é mais bem desenvolvida por Bakhtin no pequeno texto Arte e Responsabilidade, publicado originalmente em 1919, e integrado posteriormente ao livro Estética da Criação Verbal (2003). Aquele pequeno, mas denso artigo traz umas das mais profundas reflexões do autor acerca das implicações entre arte e vida desde a responsividade de qualquer pessoa/sujeito: "pelo que vivenciei e compreendi na arte, devo responder com a minha vida para que todo o vivenciado e compreendido nela não permaneçam inativos" (Bakhtin, 2003, p.XXXIII). A responsibilidade, compartilhando do neologismo proposto por Sobral (2005) para caracterizar a posição do agente de um ato (estético ou não), traz o duplo sentido: do sujeito ser responsivo, porque, uma vez que está sempre situado no mundo e em relação a outros, ao agir, responde a alguém ou a alguma coisa, e também de ser responsável por seus atos, pois "não podemos mostrar nosso álibi no acontecimento do existir» (Bakhtin, 2003, p.190). A questão da responsibilidade perpassa a própria concepção de linguagem do Círculo de Bakhtin, considerando-se que, para o grupo, todo ato discursivo, seja ele verbal ou não verbal, é sempre produzido em relações dialógicas, ou seja, na tensão entre diferentes vozes sociais e como resposta aos muitos outros, presentes ou ausentes, que nos interpelam na condição de interlocutores (Faraco, 2009a).

Segundo a teoria do enunciado concreto, desenvolvida pelo Círculo do Bakhtin (Souza, 2002; Faraco, 2009a), a linguagem não é uma estrutura morta da língua, mas um acontecimento da vida 
que vive no processo de interação dos participantes da enunciação (Voloshinov \& Bakhtin, 1976). Os autores mostram que em toda forma de discurso, qualquer locução é a expressão e o produto de uma relação triádica entre autor, ouvinte e herói, ou seja, entre o falante, o interlocutor e o tópico (o que ou o quem) da fala.

E no caso do discurso artístico? Trata-se de um modo específico de comunicação, que se caracteriza justamente pela mediação da obra de arte: "o artístico é uma forma especial de inter-relação entre criador e contemplador fixada em uma obra de arte" (Voloshinov \& Bakhtin, 1976, p.4). É por meio da sua obra que o artista fala algo para o público, o qual, na condição de ouvinte, é um coparticipante de sua produção. 0 público, não necessariamente concreto, é entendido como ouvinte imanente $\left.{ }^{5[\mathrm{~g}}\right]$ para o qual a obra se dirige e a quem responde. A partir daí, não é possível considerar o estético como atributo essencial de um objeto qualquer, já que é apenas na interação de autor e espectador que uma obra vem a ser reconhecida e afirmada como arte.

0 que distingue a comunicação estética frente ao discurso na vida é o fato de ela ser "totalmente absorvida na criação de uma obra de arte, e nas suas contínuas recriações por meio da cocriação dos contempladores, e não requer nenhum outro tipo de objetivação" (Voloshinov \& Bakhtin, 1976, p.4). Os autores frisam, assim, a irredutibilidade do discurso artístico a outras formas de comunicação ideológica (política, moral, científica, etc), o que não significa que não possa com elas dialogar, posto que a arte não existe isolada da vida social, mas participando do seu fluxo contínuo.

Segundo Voloshinov e Bakhtin (1976), na vida, na comunicação cotidiana, o enunciado verbal é diretamente relacionado ao contexto, ou seja, dependente da situação pragmática extraverbal que envolve os falantes e de sua avaliação comum dessa situação. Já o discurso na arte nasce a partir da avaliação do

\footnotetext{
5 Para Voloshinov e Bakhtin (1976), o ouvinte é “...um participante imanente do evento artístico que tem efeito determinativo na forma da obra desde dentro. 0 ouvinte, a par com o autor e o herói, é um fator intrínseco essencial,da obra, e de modo algum coincide com o assim chamado público leitor, localizado fora da obra, cujos gostos artísticos e exigências podem ser conscientemente levados em conta" (p.14).
}

autor em relação ao seu herói, isto é, ao tema de seu enunciado ou à personagem, no caso, da literatura. A avaliação do autor referente ao conteúdo de que trata sua obra (seja ela um conto, uma poesia, uma pintura, uma música, uma dança) se expressa na própria forma: "pela mediação da forma artística, o criador assume uma posição ativa com respeito ao conteúdo" (Voloshinov \& Bakhtin, 1976, p.11). Com a questão do autor e da forma, adentramos propriamente o problema da enformação estética.

Para Bakhtin (2003), "O autor ocupa uma posição responsável no acontecimento do existir" (p.176), pois trabalha sobre elementos desse acontecimento e, por isso, sua obra instaura ali um momento único e singular. Um aspecto inerente ao autor é que sua criação sempre se dá a partir de certa posição axiológica, termo que se refere à dimensão avaliativa presente em todo ato estético, pois opera sobre sistemas de valores transpondo-os a um novo plano (Faraco, 2009a). Nesta perspectiva, compreende-se que "Na atividade estética o sujeito responde criativamente à realidade dada do mundo, criando uma outra realidade, um mundo estético" (Reis, 2010, p.58). Uma experiência de vida, um evento vivido ou um simples sentimento, ao ser transposto para a arte, convertido em poesia, por exemplo, ganha outros contornos, outra cor, outro sabor, outro sentido e valor ao ser redimensionado no plano estético: "O ato estético dá à luz o existir em um novo plano axiológico do mundo..." (Bakhtin, 2003, p.177). No processo de criação estética, representar a vida na arte não é refleti-la, imitá-la, duplicá-la, mas reapresentá-la sob outras faces, ressignificá-la, transformá-la. Como explica Faraco (2009a), ao discorrer sobre a noção de autor na estética bakhtiniana:

0 autor criador é, assim, quem dá forma ao conteúdo: ele não apenas registra passivamente os eventos da vida (...), mas, a partir de certa posição axiológica, recorta-os e reorganiza-os esteticamente. $\mathrm{O}$ ato criativo envolve, desse modo, um complexo processo de transposições refratadas da vida para a arte... ( FARACO, 2009, p.90).

O problema da refração da vida na arte, de como na arte a vida é transformada, apresentada de outros modos, está atrelado à questão da enformação estética. Como, então, determinado conteúdo é trabalhado pelo autor, com sua técnica e sensibilidade, ganhando uma forma artística? Para Bakhtin 
(2003), o trabalho do autor consiste em visar o conteúdo, enformá-lo e concluí-lo através de um determinado material (verbal, no caso da literatura ou poesia, tintas e tela em uma pintura, movimentos corporais em uma dança, etc.), subordinando-o ao seu desígnio artístico. A atividade criadora é o processo de enformação estética de um conteúdo a partir de um certo material, dando-lhe um determinado acabamento estético. A enformação diz respeito à interpenetração entre a forma e o conteúdo, que é por ela encarnado (Bakhtin, 1993). A questão do acabamento estético é central para se compreender a relação entre arte e vida na visão de Bakhtin (2003): enquanto o mundo vivido é sempre aberto, pois nele cada acontecimento está sempre por vir e seu sujeito protagoniza uma história inacabada, no mundo da personagem, fruto da criação do autor, nenhum elemento que compõe sua história é fortuito. Desde a imagem externa até a "alma" do herói, cada ação, assim como o ambiente onde transcorre, é transgrediente a ele próprio, sendo determinado pelo autor. Neste sentido, entende-se que a atividade criadora recorta elementos do mundo da vida, enformando-os em um outro plano e lhes um acabamento, isto é, uma unidade ou totalidade que se corporifica na própria forma artística (Faraco, 2009b).

$\mathrm{Na}$ atividade estética, o autor "é o agente da unidade tensamente ativa do todo acabado, do todo da personagem e do todo da obra, e este é transgrediente a cada elemento particular desta" (Bakhtin, 2003, p.10). 0 autor-criador é o agente do acabamento estético, é ele que conclui a personagem e a obra. Para isso, entretanto, necessita estar em uma posição exotópica, conceito bakhtiniano que concerne ao distanciamento do autor em relação à personagem, ao tempo, espaço, sentidos e valores, necessária para que possa abarcar integralmente o herói e completá-lo. Ao distanciar-se do vivido, o movimento exotópico funda a possibilidade do excedente da visão estética do autor. Tal conceito é bem explicado por Amorim (2006) quando afirma que "A delimitação do artista dá um sentido ao outro, fornecendo uma visão do outro que lhe é completamente inacessível. Não posso me ver como totalidade, não posso ter uma visão completa de mim mesmo, e somente um outro pode construir um todo que me define" (p.96). A noção aparentemente complexa de excedente de visão, na verdade, remete a algo simples: a impossibilidade do eu de se ver enquanto um todo, pois o que o outro vê sobre ele é sempre mais do que aquilo que possa ver de si mesmo. Isso acontece em nosso dia a dia, muitas vezes em situações banais, como quando alguém avisa você de um desalinho em sua roupa ou, em ocasiões especiais, como quando todos assistem admirados a sua entrada triunfal em um evento importante, enquanto a própria pessoa só poderá se ver quando, posteriormente, contemplar os registros imagéticos, se houver.

No caso da arte, o excedente de visão do autor se objetiva, por assim dizer, na obra, pois ela expressa a concepção única do artista sobre certo tema ou personagem. Sua visão singular objetiva-se através do modo como organiza uma série de elementos transgredientes (plástico-picturais, semânticos, valorativos) que são introduzidos na vida, assim reinventada na arte. Para Bakhtin (2003), é precisamente esse excesso dadivoso do criador que constitui a "divindade" do artista, cujo objetivo maior seria "Encontrar o enfoque essencial à vida de fora dela (...) Com isso o artista e a arte criam, em linhas gerais, uma visão absolutamente nova do mundo, uma imagem do mundo que não é conhecida de nenhum dos outros ativismos criativo-culturais" (p.176).

Os ativismos a que se refere o autor remetem à própria arquitetônica bakhtiniana, que concebe o mundo a partir de três dimensões principais da cultura e atividade humanas, inexoravelmente interligadas e mutuamente constitutivas: a estética (arte), a cognitiva (ciência) e a ética (vida). Diferenciando a estética em relação às demais esferas, Bakhtin (1993) lhe atribui como particularidade o caráter receptivo e acolhedor frente à realidade, que se torna parte constitutiva da obra de arte, ainda que ao ser enformada esteticamente essa realidade seja submetida a uma refração. Faraco (2009b) considera o autor-criador como uma "posição refratada e refratante" (p.108). Assim como através de um prisma que decompõe a luz em sete cores, a obra por ele criada expressa a vida de um modo outro.

A relação entre arte e vida é, portanto, dialógica, posto que marcada pela tensão permanente entre diferentes vozes, não só as do autor e da personagem, mas dos diversos outros com os quais se comunica. Como reconhece Bakhtin (1993), "de fato, a vida não se encontra só fora da arte, mas também nela, no seu interior, em toda a plenitude de seu peso axiológico: social, político, cognitivo ou outro que seja" (p.33). Com isso entendemos que ele reafirma o vínculo existente entre arte e vida, cujo 
entrelaçamento (re)constrói a trama do vivido em forma de drama, de comédia, de epopeia ou de tragédia, realidade e ficção (re)unidas numa só trança, que enlaça o espectador, a ver a verdade que lhe transpassa na divina ilusão da arte.

Bakhtin (1993), no entanto, faz uma ressalva: não considera que a atividade estética crie, de fato, uma realidade inteiramente nova, ainda que reconheça sua autonomia e originalidade ao lado do campo ético ou do cognitivo. 0 que ele pontua é o caráter do estético: "a atividade estética cria a sua própria realidade, na qual a realidade do conhecimento e do ato se apresenta positivamente admitida e transformada: nisso consiste a singularidade do campo estético" (p.33). Em síntese, podemos afirmar que na visão de Bakhtin arte e vida se (re)constituem em uma inter-relação dialética e dialógica, na qual a atividade criadora recria a realidade, transformando-a à medida em que lhe atribui um acabamento no processo de enformação estética da obra artística.

\section{Considerações Finais}

A visão inovadora de arte e dos processos de criação e recepção estética apresentados por Vygotsky e Bakhtin abre à psicologia um rico campo, tanto de pesquisa quanto de atuação. Temos dialogado com as obras dos autores russos no sentido de (re)afirmar a potência da arte no processo de devir, de reinvenção da vida em uma perspectiva estética da existência, na qual a própria vida é reconhecida como obra inacabada que nos convoca à sua constante criação.

A arte promove o desenvolvimento psicossocial do sujeito em múltiplos aspectos, tais como a imaginação, a sensibilidade, a criatividade, a memória, as emoções e a linguagem. Além disso, pode propiciar novos modos de subjetivação pois, na experiência estética, há uma abertura à alteridade. Seja na área da psicologia da educação, da clínica ou da psicologia social, a arte pode constituir valiosa mediação nos processos de (re)constituição do sujeito.

Arte, por conseguinte, não se restringe a um campo específico do humano e o que a caracteriza não são somente objetos reconhecidos como obras de arte. A arte se institui a partir da vida, recolhendo desta os materiais para sua produção, sejam estes palavras, impressões, movimentos, imagens. Estas podem ser banais, como o mictório utilizado por Marcel Duchamp para compor a obra "A Fonte" que tanto ruído provocou no universo das artes (Speroni, 2005; Paz, 2007), ou corriqueiros, como as fotografias de transeuntes anônimos produzidas por Hans Eijkelboo e que, condensadas em uma única obra - "Foto anotações - Uma seleção do diário fotográfico 1992-2012", referida no início deste artigo - alçam a outra condição do aparentemente comum e provocam sensibilidades. São obras com a potência de instituir fissuras nos modos de ver, pensar, ouvir, sentir. Obras que, como tantas outras artes, recolhem da vida o material de sua criação, instituindo possibilidades outras para seus próprios artífices e para as pessoas que venham a com essas obras se relacionar esteticamente. Vida/arte/vida em intensa e incessante dialogia, a mover a própria existência e alçá-la a patamares outros.

\section{Referências bibliográficas}

Amorim, M. (2006). Cronotopo e exotopia. In Brait, B. (Org.). Bakhtin: outros conceitos-chave (pp. 95-114). São Paulo: Contexto.

Bakhtin, M. M. (1993). Questões de estética e de literatura. (3a ed.). São Paulo: Unesp.

Bakhtin, M. M. (2003). Estética da Criação Verbal. (4a ed.). São Paulo: Martins Fontes.

Barros, J. P. P. (2012a). Contribuiç̧ões de Vigotski e Bakhtin para o conceito de "social" na Psicologia. Pesquisas e Práticas Psicossociais, 7 (1), 121-129.

Barros, J. P. P. (2012b) Constituição de sentidos e subjetividades : aproximações entre Vigotski e Bakhtin. ECOS-Estudos Contemporâneos da Subjetividade, 2, 133-146.

Canevacci, M. (2008). Fetichismos Visuais: corpos erópticos e metrópole comunicacional. São Paulo: Ateliê Editorial.

Da Ros, S. Z., Zanella, A. V., \& Maheirie, K. (2006). Relações estéticas, atividade criadora e imaginação: sujeitos e/ em experiência. Florianópolis: Editora da UFSC, NUP/ CED/UFSC.

Faraco, C. A. (2009a). Linguagem e diálogo: as ideias linguísticas do Círculo de Bakhtin. São Paulo: Parábola Editorial. 
Faraco, C. A. (2009b). O problema do conteúdo, do material e da forma na arte verbal. In: B. Brait (Org.). Bakhtin, dialogismo e polifonia (pp.95-111). São Paulo: Contexto.

Paz, O. (2007). Marcel Duchamp, ou o castelo da pureza. São Paulo: Perspectiva.

Reis, A. C., Zanella, A. V., França, K. B., \& Da Ros, S. (2004). Mediação pedagógica: reflexões sobre o olhar estético em contexto de escolarização formal. Psicologia: Reflexão e Crítica, 17 (1), 51-60.

Reis, A. C. (2010). Dançar a vida: a constituição do sujeito como devir estético. In A. V. Zanella \& K. Maheirie (Orgs.). Diálogos em Psicologia Social e Arte (pp. 5168). Curitiba: CRV.

Sobral, A. (2005). Ato, atividade e evento. In: Brait, B. (Org.). Bakhtin: conceitos-chave (pp.11-36). São Paulo: Contexto.

Sontag, S. (2004). Sobre Fotografia. São Paulo: Companhia das Letras.

Souza, G. T. (2002). Introdução à teoria do enunciado concreto: do círculo Bakhtin/Volochinov/Medvedev. (2a ed.). São Paulo: Humanitas/FFLCH/USP.

Speroni, F. (2005). Sotto il nostro sguardo: per una lettura mediale dell'opera d'arte. Milano: Costa \& Nolan.

Vygotsky, L. S. (1990). La imaginacion y el arte em la infância. Madri: Akal.

Vygotsky, L. S. (1998). Psicologia da Arte. São Paulo: Martins Fontes.

Vygotsky, L. S. (2000). Manuscrito de 1929. Educação \& Sociedade, 21 (71), 23-44.
Vygotsky, L. S. (2001). Psicologia Pedagógica. São Paulo: Martins Fontes.

Voloshinov, V. N., \& Bakhtin, M. M. (1976). Discurso na vida e discurso na arte. Tradução não publicada de C. Faraco e C. Tezza, para uso didático, da tradução inglesa de I.R.Titunik, publicada em V.N. Voloshinov (1976), Freudism. New York: Academic Press.

Wilde, O. (1992). Intenções: Quatro Ensaios sobre Estética. Lisboa: Edições Cotovia.

Zanella, A. V. (1995). A Ideologia Alemã: resgatando pressupostos epistemológicos da abordagem histórico-cultural. Psico, 26 (1), 187-194.

Zanella, A. V., Da Ros, S. Z., Reis, A. C., \& França, K. B. (2003). Concepções de Criatividade: movimentos em um contexto de escolarização formal. Psicologia em Estudo, 8 (1), 143-150.

Zanella, A. V., Reis, A. C., Camargo, D., Maheirie, K., França, K. B., \& Da Ros, S. Z. (2005). Movimento de Objetivação e Subjetivação, mediado pela criação artística. Psico-USF, 10 (2), 191-199.

Zanella, A. V. (2005). Sujeito e alteridade: reflexões a partir da psicologia histórico-cultural. Psicologia $e$ Sociedade, 17 (2), 99-104.

Zanella, A. V. (2006). Pode até ser flor se flor parece a quem o diga: reflexões sobre educação estética e o processo de constituição do sujeito. In S. Da Ros, A. V. Zanella, \& K. Maheirie (Orgs.). Relações estéticas, atividade criadora e imaginação: sujeitos e/em experiência (pp.33-47). Florianópolis: Editora da UFSC, NUP/CED/UFSC.

Zanella, A. V., \& Maheirie, K. (2010). Diálogos em Psicologia Social e Arte. Curitiba: CRV. 